\title{
The effect of paroxetine on thiothixene pharmacokinetics
}

\author{
S. K. Guthrie PharmD*t, M. Hariharan PhD†, A. A. Kumar*, G. Bader MD† and R. Tandon MD† \\ *College of Pharmacy, The University of Michigan, and +Department of Psychiatry, The University of Michigan \\ Medical School, Ann Arbor, MI 48109, U.S.A.
}

\section{SUMMARY}

Objective: In this study healthy volunteers received thiothixene with and without a 3 -day pretreatment with paroxetine to determine if paroxetine decreased the clearance of thiothixene. Method: Ten healthy medication-free volunteers (4 women and 6 men, mean age $38 \pm 12$ years) were randomized to receive a single $20 \mathrm{mg}$ oral dose of thiothixene on two separate occasions. On one occasion thiothixene was given concurrently, and following 3 days of pre-treatment with oral paroxetine $(20 \mathrm{mg} /$ day $)$. On the other occasion thiothixene was given without paroxetine pretreatment. The two study days were separated by a minimum period of 2 weeks. On both study days, after the administration of thiothixene, $10 \mathrm{ml}$ blood samples were collected over the next $72 \mathrm{~h}$.

Results: None of the pharmacokinetic parameters of thiothixene were significantly altered by a 3-day treatment with paroxetine.

Discussion: It is likely that the CYP2D6 isoenzyme is not responsible for a high proportion of thiothixene clearance, but one cannot exclude the possibility that a longer paroxetine pretreatment might have caused some inhibition of thiothixene clearance.

\section{INTRODUCTION}

Since their marketing in the late 1980s, it has become apparent that the serotonin specific re-uptake inhibitors (SSRIs) can interfere with the oxidative metabolism of many drugs that are biotransformed via the cytochrome P450 (CYP450) enzymes. While full profiles of enzymatic inhibition have not yet been defined for all the SSRIs, such information has been

Correspondence: Sally K. Guthrie, Associate Professor of Pharmacy, College of Pharmacy, The University of Michigan, 428 Church Street, Ann Arbor, MI 48109-1065, U.S.A. partially delineated. For instance, it is known that fluoxetine and norfluoxetine are potent inhibitors of CYP2D6 $(1,2)$, mild to moderate inhibitors of CYP3A3/4 $(3,4)$, and they also possibly cause some inhibition of CYP2C (5) isoenzymes. Fluvoxamine is a potent inhibitor of CYP1A2 $(6,7)$, a mild to moderate inhibitor of CYP3A3/4 $(4,8)$, but causes only minimal inhibition of CYP2D6 (9). Sertraline causes mild to moderate inhibition of CYP2D6 (10) and CYP3A3/4 (11). Paroxetine appears to exhibit rather selective and potent inhibition of CYP2D6 $(4,12,13)$. It is generally assumed that most antipsychotics are at least partially metabolized via the CYP2D6 isoenzymatic pathway. However, with the exception of risperidone (14), haloperidol $(15-17)$ and clozapine $(18,19)$, little is known about the enzymatic pathways by which most of the antipsychotics are biotransformed. Thiothixene, which differs structurally from the phenothiazines, is a good example of this. Investigators who conducted metabolism studies in the 1970s found that thiothixene is metabolized to a desmethyl and a sulfoxide metabolite (20), but the pathways that mediate these biotransformations are unknown at this time. This study is an investigation of the effect of paroxetine on thiothixene pharmacokinetics.

\section{MATERIALS AND METHODS}

All volunteers for this study were medically healthy, white, non-smokers between the ages of 18 and 65 years who were recruited using newspaper advertisements. This study protocol was approved by the University of Michigan Medical Centre Institutional Review Board, and upon agreement to participate in the study all volunteers signed a written informed consent form. Following a physical examination, clinical laboratory studies were conducted, including CBC, electrolytes, liver function studies, urinalysis and serum pregnancy tests for all pre-menopausal women. Volunteers did not have a history of any chronic 
medical illness, nor had any used drugs known to induce or inhibit hepatic enzymes within 1 month of the study. None of the subjects were currently taking prescription medications or over-the-counter medications. All volunteers also underwent urine toxicology screening to exclude use of abused substances. All female volunteers were post-menopausal, had undergone tubal ligation or were using an effective form of barrier contraception (none were taking oral contraceptives). Subjects abstained from alcohol use for at least $48 \mathrm{~h}$ prior to the beginning of the study, and for the duration of both phases of the study. During the study a single cup of caffeinated beverage was allowed with breakfast if desired.

Volunteers were studied on two occasions (Phase I and Phase II) separated by a minimum period of 2 weeks. For both phases of the study the volunteers were admitted to the General Clinical Research Centre (GCRC), which is located in the University of Michigan Medical Centre, for a 24-h inpatient stay. Following both admissions to the GCRC, volunteers received a $20 \mathrm{mg}$ capsule of cis-thiothixene (Navane, Roerig) and a $2 \mathrm{mg}$ tablet of biperiden (Akineton, Knoll) between 8 and 9 Am. Additional $2 \mathrm{mg}$ doses of biperiden were administered at 8 PM that evening and at $8 \mathrm{AM}$ and $8 \mathrm{PM}$ the following day, to prevent thiothixene-induced extrapyramidal symptoms. Shortly after admission to the inpatient unit an intravenous catheter was placed in a forearm vein for blood drawing.

In Phase I, the thiothixene was not accompanied by paroxetine. During Phase II, the volunteer received 3 days of paroxetine (Paxil, Smithkline Beecham) at a dose of $20 \mathrm{mg} /$ day prior to inpatient admission to the GCRC, plus an additional $20 \mathrm{mg}$ tablet of paroxetine along with the thiothixene on the day of admission. All oral doses of thiothixene, biperiden and paroxetine were taken from the same bottles for all volunteers. The order in which volunteers participated in Phase I or Phase II of the study was randomized.

To determine thiothixene serum concentrations, blood was drawn into heparinized green topped vacutainers $(10 \mathrm{ml})$ at baseline, and at $10,20,30$ and $45 \mathrm{~min}$, then at $1,1.5,2,3,4,6,8,12,24,48$ and $72 \mathrm{~h}$ following the thiothixene dose. Samples were centrifuged and plasma was stored at $-20^{\circ} \mathrm{C}$ until assay. Cis-thiothixene was quantified by an HPLC method using an electrochemical detector (21). Trifluoperazine was used as the internal standard in the assay. The plasma was made alkaline with ammonium hydroxide and the analytes extracted using $6 \mathrm{ml}$ of pentane-isopropanol mixture (95:5 v:v). The mixture was centrifuged and the top organic layer was transferred to a second Teflon tube. Thiothixene was back extracted from the organic solvent using $2 \mathrm{ml}$ of $0 \cdot 1 \mathrm{M}$ perchloric acid. After centrifugation of this mixture the top organic layer was aspirated off, the aqueous solution was alkalinized with ammonia and agitated with the pentane-isopropanol mixture. After centrifugation the top organic layer was carefully transferred to another clean Teflon tube and evaporated under nitrogen in a water bath at $45^{\circ} \mathrm{C}$. The dry residue was reconstituted in $50 \mathrm{ml}$ of acetonitrile and 20-40 $\mathrm{ml}$ was injected into the HPLC system. The HPLC method utilized a $5 \mu \mathrm{m}$ cyano-propyl column $(25 \times 0.46 \mathrm{~cm}$; Altex Ultrasphere, Arlington Heights, IL, U.S.A.), and a coulometric electrochemical detector (Environmental Science Associates, Bedford, MA, U.S.A.). The mobile phase consisted of a 40:60 (v:v) of monobasic potassium phosphate $(10 \mathrm{mmol} / \mathrm{l}, \mathrm{pH} 2 \cdot 5)$ and acetonitrile. The mobile phase flow rate was $2.5 \mathrm{ml} / \mathrm{min}$. The assay sensitivity was $200 \mathrm{pg} / \mathrm{ml}$ for cis-thiothixene, and the inter-assay coefficient of variation was less than $10 \%$ for the concentration range $1-40 \mathrm{ng} / \mathrm{ml}$.

Pharmacokinetic parameters were calculated from thiothixene plasma concentrations using both compartmental and non-compartmental methods. The area under the plasma concentration versus time curve from 0 to $72 \mathrm{~h}\left(A U C_{0-72}\right)$ was calculated using the trapezoidal rule, and oral clearance $\left(C_{\mathrm{po}}\right)$ was calculated by dividing dose by $A U C_{0-72} . C_{\mathrm{po}}$ was adjusted by volunteer weight. Using PCNonlin (22) the data were fitted to a two compartment model with oral absorption and the best fits for $\mathrm{A}, \mathrm{B}, \alpha, \beta$ and $K_{\mathrm{a}}$ were estimated. Elimination half-life $\left(t_{1 / 2}\right)$ was calculated using $0.693 / \beta$. The maximum plasma concentration $\left(C_{\max }\right)$ and the time of maximum plasma concentration $\left(t_{\max }\right)$ were determined by visual examination of the data. To determine if there was a statistically significant difference between $A U C_{0-72}, C_{\mathrm{po}}$ and $t_{1 / 2}$ with and without paroxetine, the results following both phases of the study were compared using the paired Student's t-test (23).

\section{RESULTS}

Ten volunteers completed both phases of the study. Of these, there were four women and six men, and the 
Table 1. Thiothixene pharmacokinetics in 10 normal volunteers with or without concomitant paroxetine

\begin{tabular}{lrl}
$\begin{array}{l}\text { Pharmacokinetic } \\
\text { variable }\end{array}$ & $\begin{array}{l}\text { Without paroxetine } \\
(\mathrm{x} \pm \mathrm{SD})\end{array}$ & $\begin{array}{l}\text { With paroxetine } \\
(\mathrm{x} \pm \mathrm{SD})\end{array}$ \\
\hline$A U C_{0-72}(\mathrm{ng} / \mathrm{ml} / \mathrm{h})$ & $117 \cdot 0 \pm 87 \cdot 8$ & $98 \cdot 6 \pm 86 \cdot 7$ \\
$C_{\mathrm{po}}(\mathrm{L} / \mathrm{h} / \mathrm{kg})$ & $7 \cdot 23 \pm 13 \cdot 2$ & $5 \cdot 69 \pm 5 \cdot 26$ \\
$t_{1 / 2}(\mathrm{~h})$ & $13 \cdot 7 \pm 9 \cdot 03$ & $19 \cdot 1 \pm 18 \cdot 1$ \\
$C_{\max }(\mathrm{ng} / \mathrm{ml})$ & $27 \cdot 2 \pm 24 \cdot 6$ & $22 \cdot 2 \pm 15 \cdot 2$ \\
$t_{\max }(\mathrm{h})$ & $2 \cdot 2 \pm 1 \cdot 1$ & $1 \cdot 75 \pm 0 \cdot 8$ \\
\hline
\end{tabular}

mean age $( \pm S D)$ was $38 \pm 12$ years. All volunteers tolerated the study protocol relatively well and no unexpected effects were noted, although some volunteers complained of sedation following thiothixene and one volunteer experienced nausea while receiving paroxetine. Also, although biperiden prophylaxis prevented the occurrence of acute dystonic reactions in the patients, several volunteers complained of mild to moderate akathisia.

Since the only prior estimate of thiothixene elimination $t_{1 / 2}$ was $35 \mathrm{~h}$, we measured blood concentrations up to $72 \mathrm{~h}$ to try and capture as much data as possible for calculations of AUC. Although the assay used in this study was sensitive to $200 \mathrm{pg} / \mathrm{ml}$, some volunteers had undetectable blood levels at the later time points $(>24 \mathrm{~h})$.

Although considerable variability was seen in $C_{\max }$ it was not consistently altered by paroxetine. Likewise, $t_{\max }$ was not significantly different when paroxetine was added (Table 1). The $C_{\mathrm{po}}, A U C_{0-72}$ and $t_{1 / 2}$ elimination also showed considerable interindividual variability amongst the volunteers. One volunteer clearly exhibited a much more rapid $\mathrm{C}_{\mathrm{po}}$ of thiothixene, both without and during concomitant paroxetine administration (Fig. 1). However, overall there were no statistically significant differences in any of the pharmacokinetic parameters when paroxetine was administered.

\section{DISCUSSION}

There are many instances in which antidepressants, such as SSRIs, and antipsychotics might be used concomitantly. Combinations of antipsychotics and antidepressants are commonly used to treat depression complicated by psychotic features, schizoaffective disorder, the depressive pole of bipolar disease, and schizophrenic patients who also suffer from depressive symptoms. In several cases SSRIs have caused an increase in antipsychotic blood concentrations when this combination of agents was given concomitantly. Both fluvoxamine and fluoxetine, when combined with haloperidol, have increased haloperidol levels $(24,25)$; and fluvoxamine has also increased clozapine blood levels (26). Although many of the commonly used antipsychotics, such as thioridazine (27), perphenazine (28) and risperidone (14), are biotransformed via CYP2D6, almost nothing is known about the isoenzymatic pathways important for the metabolism of thiothixene.

Only a small amount of study has been devoted to the pharmacokinetics of thiothixene in comparison with other antipsychotics, possibly due to the difficulties in accurately assaying the drug. Hobbs et al. (29) used mass fragmentography to determine thiothixene pharmacokinetics and found that plasma concentrations varied from 10 to $22 \mathrm{ng} / \mathrm{ml}$ when they were drawn $2-2.5 \mathrm{~h}$ following the previous dose in patients who were taking $15-60 \mathrm{mg} /$ day of thiothixene. The mean elimination $t_{1 / 2}$ in this study was approximately $35 \mathrm{~h}$. In the present study, the mean elimination $t_{1 / 2}$ was $16.4 \pm 14.2 \mathrm{~h}$, although the range was quite large $(5 \cdot 8-69 \cdot 3 \mathrm{~h})$.

In the most recent study of thiothixene pharmacokinetics, oral clearance of thiothixene using highperformance thin-layer chromatography (HPTLC) was determined in 42 patients (30). In this study, patients were divided into groups who were receiving known enzyme inducers, known enzyme inhibitors and those who where not receiving either. They were further divided into smoking versus non-smoking groups. Smoking caused a highly significant increase in $C_{\text {po }}$ in the population as a whole, which would suggest the importance of the CYP1A2 pathway for thiothixene metabolism (31). Furthermore, the group receiving enzyme inhibitors exhibited a significant reduction in thiothixene clearance when compared with the group receiving neither inducers nor inhibitors. However, while the inhibiting drugs included isoniazid, cimetidine and propranolol, no mention was made of any of the SSRIs. It is likely that they were not widely available at the time this study was conducted. The values for oral clearance in the above study were generally higher than ours. The difference in $C_{\text {po }}$ values between that study and ours might possibly be 

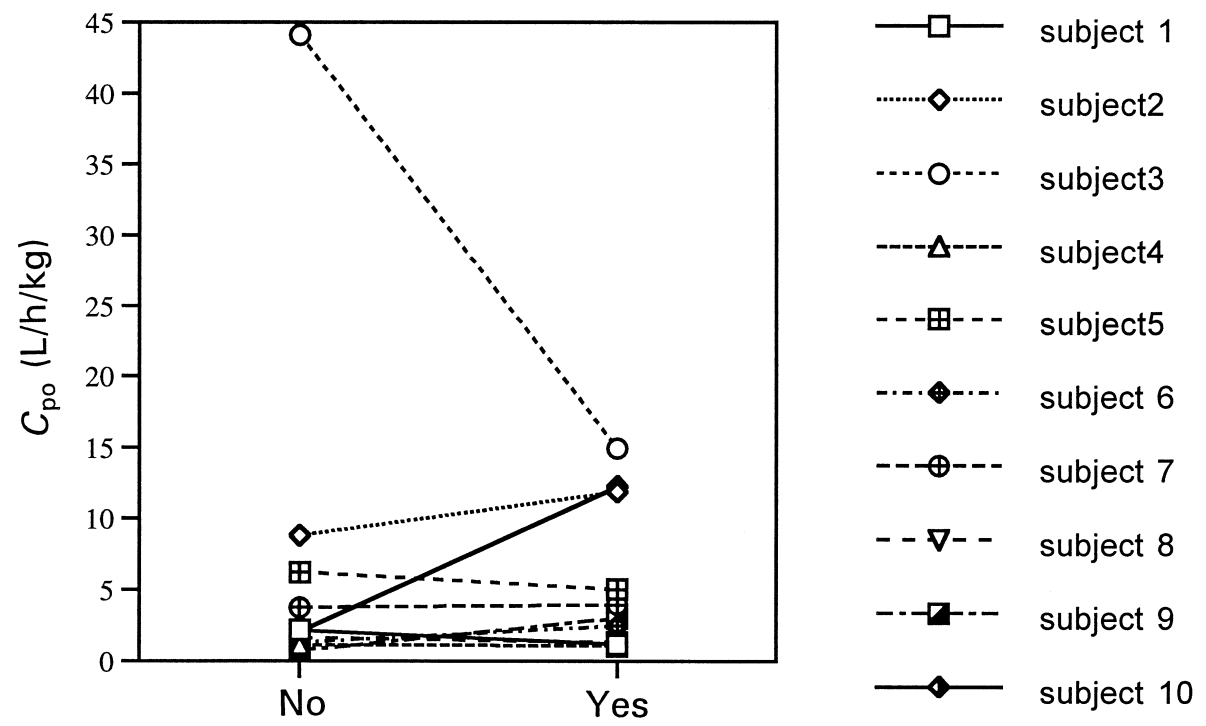

Fig. 1. Cis-thiothixene oral clearance with or without paroxetine.

ascribed to different assay methodologies, differences in study population, or to the intrinsic properties of thiothixene. Although it is unknown if thiothixene undergoes linear clearance over time and over increasing doses, it is would seem unlikely that thiothixene induces its own metabolism during chronic treatment. While antipsychotics have often been implicated as inhibitors of hepatic metabolism, there are no data indicating that any of them are enzyme inducers.

O ur results indicate that paroxetine does not impair the oral clearance of thiothixene. Since paroxetine is a potent and relatively specific inhibitor of CYP2D6, this would seem to indicate that the CYP2D6 is not an important biotransformational enzyme for thiothixene. There are several other, but less likely, possibilities. It is possible that all of the volunteers except the one who had a very high $C_{\text {po }}$ of thiothixene possessed the debrisoquine/sparteine slow hydroxylator phenotype, i.e. they were deficient in CYP2D6. Since our population was entirely white and the incidence of the slow hydroxylation phenotype is approximately $7 \%$ among white people (32), it could be expected that one of our volunteers might have been a slow hydroxylator, but the probability of $9 / 10$ being slow hydroxylators was extremely low. However, this cannot be determined with certainty since CYP2D6 phenotyping was not carried out in our volunteers.

Another possibility might be that biperiden inhibited CYP2D6 and additional inhibition with paroxetine was not detectable. There is little data regarding the effects of biperiden on the pharmaco- kinetics of antipsychotics. It is known that biperiden does not inhibit the metabolism of remoxipride (33), nor does it cause alterations of average steady state blood levels of haloperidol (34), thioridazine (34) or perphenazine (35). Because both thioridazine and perphenazine are metabolized via CYP2D6, it is unlikely that biperiden inhibits this isoenzyme pathway. Consequently, it is unlikely that biperiden would interfere with any inhibition caused by paroxetine.

Because there may be considerable interindividual variability in the clearance of paroxetine it is possible that the subjects had not all achieved steady state paroxetine levels within 4 days. Consequently enzyme inhibition due to paroxetine may not have been maximal and a longer paroxetine dosing period might have revealed a change in thiothixene clearance. However, paroxetine is a potent inibitor of CYP2D6, and if the CYP2D6 isoenzyme is an important metabolic pathway for thiothixene, even non-steady state paroxetine concentrations should have caused a marked inhibition of thiothixene clearance.

Finally, it is possible that diet may have influenced the bioavailability and clearance of thiothixene, because diet was not standardized and all volunteers received the regular diet provided by the GCRC. Some individuals may have received grapefruit juice or other dietary items that alter enzymatic biotransformation.

This investigation of a possible drug interaction between thiothixene and paroxetine has revealed no significant interaction between these two drugs. 
This would suggest that the CYP2D6 isoenzyme may not be a particularly important biotransformational pathway for thiothixene.

\section{ACKNOW LEDGEMENTS}

This research was supported by a grant from the Department of Psychiatry at the University of Michigan and by the General Clinical Research Centre (grant \#M01 RR00042).

\section{REFERENCES}

1. Brøsen K, Skjelbo E. (1991) Fluoxetine and norfluoxetine are potent inhibitors of P450IID6-the source of the sparteine/debrisoquine oxidation polymorphism. British Journal of Clinical Pharmacology, 32, 136-137.

2. Bergstrom RF, Peyton AL, Lemberger L. (1992) $Q$ uantification and mechanism of the fluoxetine and tricyclic antidepressant interaction. Clinical Pharmacology and Therapeutics, 51, 239-248.

3. Lasher TA, Fleishaker JC, Steenwyk RC, Antal EJ. (1991) Pharmacokinetic pharmacodynamic evaluation of the combined administration of alprazolam and fluoxetine. Psychopharmacology, 104, 323-327.

4. VonMoltke LL, Greenblatt DJ, Court MH, Duan SX, Harmatz JS, Shader RI. (1994) Inhibition of alprazolam and desipramine hydroxylation in vitro by paroxetine and fluvoxamine: comparison with other selective serotonin reuptake inhibitor antidepressants. Journal of Clinical Psychopharmacology, 15, 125-131.

5. Lemberger L, Rowe H, Bosomworth JC, Tenbarge JB, Bergstrom RF. (1988) The effect of fluoxetine on the pharmacokinetics and psychomotor responses of diazepam. Clinical Pharmacology and Therapeutics, 43, 412-419.

6. Brøsen K, Skjelbo E, Rasmussen BB, Poulsen HE, Loft S. (1993) Fluvoxamine is a potent inhibitor of cytochrome P4501A2. Biochemical Pharmacology, 45, 1211-1214.

7. Rasmussen BB, Maenpaa J, Pelkonen O, Loft S, Poulsen HE, Lykkesfeldt J, Brøsen K. (1995) Selective serotonin reuptake inhibitors and theophylline metabolism in human liver microsomes: potent inhibition by fluvoxamine. British Journal of Clinical Pharmacology, 39, 151-159.

8. Fleishaker JC, Hulst LK. (1994) A pharmacokinetic and pharmacodynamic evaluation of the combined administration of alprazolam and fluvoxamine. European Journal of Clinical Pharmacology, 46, 35-39.

9. Preskorn SH, Magnus RD. (1994) Inhibition of hepatic P-450 isoenzymes by serotonin reuptake inhibitors: in vitro and in vivo findings and their implications for patient care. Psychopharmacology Bulletin, 30, 251-259.
10. Preskorn SH, Alderman J, Chung M, Harrison W, Messig M, Harris S. (1994) Pharmacokinetics of desipramine coadministered with sertraline or fluoxetine. Journal of Clinical Psychopharmacology, 14, 90-97.

11. VonMoltke LL, Greenblatt DJ, Cotreau-Bibbo MM, Harmatz JS, Shader RI. (1994) Inhibitors of alprazolam metabolism in vitro: effect of serotonin-reuptakeinhibitor antidepressants, ketoconazole and quinidine. British Journal of Clinical Pharmacology, 38, 23-31.

12. Andersen BB, Mikkelsen M, Vesterager A, Dam M, Kristensen HB, Pedersen B, Lund J, Mengel H. (1991) No influence of the antidepressant paroxetine on carbamazepine, valproate and phenytoin. Epilepsy Research, 10, 201-204.

13. Sindrup SH, Brøsen K, Gram LF, Hallas J, Skjelbo E, Allen A, Allen GD, Cooper SM, Mellows G, Tasker TCG, Zussman BD. (1992) The relationship between paroxetine and the sparteine oxidation polymorphism. Clinical Pharmacology and Therapeutics, 51, 278-287.

14. Huang M-L, VanPeer A, Woestenborghs R, DeCoster R, Heykants J, Jansen AAI, Zylicz Z, Visscher HW, Jonkman JHG. (1993) Pharmacokinetics of the novel antipsychotic agent risperidone and the prolactin response in healthy subjects. Clinical Pharmacology and Therapeutics, 54, 257-268.

15. Llerena A, Alm C, Dahl M, Ekqvist B, Bertilsson L. (1992) Haloperidol disposition is dependent on debrisoquine hydroxylation phenotype. Therapeutic Drug Monitoring, 14, 92-97.

16. Tyndale RF, Kalow W, Inaba T. (1991) Oxidation of reduced haloperidol to haloperidol: involvement of human P450IID6 (sparteine/debrisoquine monooxygenase). British Journal of Clinical Pharmacology, 31, 655-660.

17. Young D, Midha KK, Fossler MJ, Hawes EM, Hubbard JW, McKay G, Korchinski ED. (1993) Effect of quinidine on the interconversion kinetics between haloperidol and reduced haloperidol in humans: implications for involvement of cytochrome P450IID6. European Journal of Clinical Pharmacology, 44, 433-438.

18. Dahl ML, Llerena A, Bondesson U, Lindstrom L, Bertilsson L. (1994) Disposition of clozapine in man: lack of association with debrisoquin and S-mephenytoin hydroxylation polymorphisms. British Journal of Clinical Pharmacology, 37, 71-74.

19. Bertilsson L, Carrillo JA, Dahl ML, Llerena A, Alm C, Bondesson U, Linström L, Rodrigues de la Rubia I, Ramos S, Benitez J. (1994) Clozapine disposition covaries with CYP1A2 activity determined by a caffeine test. British Journal of Clinical Pharmacology, 38, 471-473.

20. Ban TA. (1978) Thiothixene Psychopharmacology. Raven Press, New York. 
21. Hariharan M, VanNoord T, Kindt EK, Tandon R. (1991) A simple, sensitive liquid chromatographic assay of cis-thiothixene in plasma with coulometric detection. Therapeutic Drug Monitoring, 13, 79-85.

22. Metzler CN, Elfring GL, McEwan AJ. (1974) A user's manual for nonlin and associated programs. Upjohn, Kalamazoo, MI, U.S.A.

23. STATVIEW, the Graphic Statistics Utility for Macintosh. (1985) Brain Power Inc., Calabasas, CA, U. S. A.

24. Goff DC, Midha KK, Brotman AW, Waites M, Baldessarini RJ. (1991) Elevation of plasma concentrations of haloperidol after addition of fluoxetine. American Journal of Psychiatry, 148, 790792.

25. Daniel DG, Randolf C, Jaskiw G, et al. (1994) Coadministration of fluvoxamine increases serum concentrations of haloperidol. Journal of Clinical Psychopharmacology, 14, 340-343.

26. Jerling $M$, Lindström $L$, Bondesson $U$, Bertilsson $L$. (1994) Fluvoxamine inhibition and carbamazepine induction of the metabolism of clozapine: evidence from a therapeutic drug monitoring service. Therapeutic Drug Monitoring, 16, 368-374.

27. Von Bahr C, Movin G, Nordin C, et al. (1991) Plasma levels of thioridazine and metabolites are influenced by the debrisoquin hydroxylation phenotype. Clinical Pharmacology and Therapeutics, 49, 234-240.

28. Dahl-Puustinen ML, Lidén A, Alm C, Nordin C, Bertilsson L. (1989) Disposition of perphenazine is related to the polymorphic debrisoquine hydroxylation in man. Clinical Pharmacology and Therapeutics, 46, $78-81$
29. Hobbs DC, Welch WM, Short MJ, Moody WA, van der Velde CD. (1974) Pharmacokinetics of thiothixene in man. Clinical Pharmacology and Therapeutics, 16, 473-478.

30. Ereshefsky L, Saklad SR, Watanabe MD, Davis CM, Jann MW. (1991) Thiothixene pharmacokinetic interactions: a study of hepatic enzyme inducers, clearance inhibitors, and demographic variables. Journal of Clinical Psychopharmacology, 11, 296-301.

31. Sesardic D, Boobis AR, Edwards RJ, Davies DS. (1988) A form of cytochrome P450 in man, orthologous to form $d$ in the rat catalyses the $\mathrm{O}$-deethylation of phenacetin and is inducible by cigarette smoking. British Journal of Clinical Pharmacology, 26, 363-372.

32. Bertilsson L, Lou YQ, Du YL, et al. (1992) Pronounced differences between native Chinese and Swedish populations in the polymorphic hydroxylations of debrisoquine and S-mephenytoin. Clinical Pharmacology and Therapeutics, 51, 388-397.

33. Yisak W, Farde L, von Bahr C, Nilsson LB, Fredriksson G, Ogenstad S. (1993) Interaction study between remoxipride and biperiden. Psychopharmacology, 111, 27-32.

34. Linnoila M, Viukari M, Vaisanen K, Auvinen J. (1980) Effect of anticonvulsants on plasma haloperidol and thioridazine levels. American Journal of Psychiatry, 137, 819-821.

35. Bolvig Hansen L, Elley J, Rosted Christensen T, Larsen N-E, Naestoft J, Hvidberg EF. (1979) Plasma levels of perphenazine and its major metabolites during simultaneous treatment with anticholinergic drugs. British Journal of Clinical Pharmacology, 7, 75-80. 